\title{
Sobre a Associação Brasileira de Enfermagem - 85 anos de história: pontuais avanços e conquistas, contribuições marcantes, e desafios
}

\author{
About the Brazilian Nursing Association - 85 years of history: \\ punctual advances and conquests, remarkable contributions, and challenges \\ Acerca de la Asociación Brasileña de Enfermería - 85 años de historia: \\ puntuales avances y conquistas, contribuciones importantes, y desafíos
}

\section{Vilma de Carvalho'}

'Universidade Federal do Rio de Janeiro, Escola de Enfermagem Anna Nery, Departamento de Enfermagem de Saúde Pública. Grupo de Pesquisa e Estudos Epistemológicos para a Enfermagem (Líder).

Submissão: 11-06-2012 Aprovação: 14-06-2012

\section{RESUMO}

Trata-se de aspectos pontuais dos 85 Anos de História da Associação Brasileira de Enfermagem (ABEn), tempo histórico-evolutivo que é um lastro quase secular. A intenção objetiva é ressaltar alguns avanços e conquistas que consagram a entidade associativa na realidade brasileira. A aproximação temática é de reflexões apreciativas, conferindo com a ideia de mudanças efetivadas em plano de desenvolvimento associativo e compromisso social, e com relevo à necessidade de apontar permanentes desafios. A posição da autora é literária e experiencial, de quem aprendeu a conhecer sua entidade de classe, na própria atividade da vida profissional de enfermeira associada e de professora de enfermagem, engajada nas programações de vários eventos que selaram o desenvolvimento da ABEn no panorama científico e social idealisticamente continuado e a desenvolver-se futuro adiante. Não se cogita de proposições visando à solução para possíveis desvios de rotas nas vertentes constitutivas da profissão, nem se pretende resolver questões cruciais vigentes. Ressalta-se a ideia de suscitar questionamentos no âmbito da entidade associativa tangível ao ideal de zelar pelos avanços da classe profissional quanto ao valor da função de enfermeiras/os face ao compromisso e responsabilidade social, e relativamente aos cuidados ofertados/prestados aos clientes e usuários do sistema de saúde.

Descritores: Enfermagem brasileira; Avanços e lutas; Contribuição e saltos evolutivos; Desenvolvimento associativo.

\begin{abstract}
This is to point upper specific aspects of the Brazilian Nursing Association 85 Years of History (ABEn), an historical-evolutionary time that is quite a secular. The most objective intention is to emphasize the advances and remarkable conquests that distinguished the associative entity in the Brazilian reality. The thematic approach is of appreciative reflections referring to the idea of considering some changes accomplished in the associative development plan and social compromise, but with emphasis to reconsider some permanent challenges. The author's position is literary and experiential, of whom could learned to know her primate class entity in the own professional life activity as associate nurse and nursing teacher committed in the plan of several events engaging the ABen developmental progress in the social-scientific sceneries rooted throughout the idealistically continuing process to be developed future ahead. One not need to think on proposals aimed solution to possible rout deviation in the constitutive structure of the profession, neither even is pretended to resolve current crucial questions. But, the raising questioning idea emphasizes that the scope developmental sphere of the associative entity is tangible to the ideal of ensuring the advances of the professional class in relation to the care offered/provided to the clients and users of the health system.
\end{abstract}

Key words: Brazilian nursing; Fighting and advances; Evolution leaps and contributions.

Conferência pronunciada na Assembléia Legislativa do Estado do Rio de Janeiro, na Sessão de Abertura da $73^{a}$. Semana Brasileira de Enfermagem, face ao tema central "Associação Brasileira de Enfermagem: 85 Anos de Compromisso Social, Participação e Luta", Rio de Janeiro-RJ, 2012 


\section{RESUMEN}

Se trata de presentar los aspectos específicos de los 85 Años de Historia de la Asociacón Brasileña de Enfermería (ABEn), en la oportunidad de la 73a Semana Brasileña de Enfermería (11 a 21 de Mayo de 2012), realizada en la Ciudad de Rio de Janeiro en la programación de la ABEn Seción RJ. El tiempo histórico-evolutivo es un lastro casi secular. La intención objetiva es la de relevar puntuales avanzos y conquistas que consagran la entidad asociativa en la realidad brasileña. La aproximación temáticas es de reflexiones consistentes con la idea de apuntar cambios efectuados en plan de desarrollo asociativo y compromiso social, y con realce en la necesidad de reconsiderar permanentes desafíos. La posición de la autora es literaria y experiencial, de uno quien aprendió a conocer su mayor entidad de clase, en la propia actividad de la vida profesional de enfermera asociada y de maestra de enfermería comprometida con las programaciones de varios eventos a justificar el desarrollo de la ABEn en el panorama científico y social aliado al proceso de idealismo continuado y a desarrollarse futuro adelante. No se cogita de presentar proposición visando soluciones mayores para posibles desvíos de rotas en las vertientes constitutivas de la profesión, y ni si pretende resolver cuestiones cruciales vigentes. Pero, resaltase la idea de suscitar cuestionamientos del ámbito de la entidad asociativa tangible a lo ideal de asegurar los avances de la clase profesional cuanto al valor de la función de enfermeras/ os ante al compromiso y responsabilidad social en relación a los cuidados ofertados/prestados a los clientes y usuarios del sistema de salud.

Palabras clave: Enfermería brasileña; Avanzos y luchas; Contribuciones y saltos evolutivos.

\section{UMA INTRODUÇÃO IMPRESCINDÍVEL}

Certamente os profissionais enfermeiras/os estão interessados em prestigiar, neste dia 11 de Maio de 2012, - quando se iniciam eventos científicos da $73^{a}$. Semana Brasileira de Enfermagem -, principalmente as comemorações dos 85 Anos da Associação Brasileira de Enfermagem (ABEn). Trata-se de lastro quase secular para falar sobre esta magnífica entidade a congregar os profissionais e demais exercentes associados. Pode ser muito no tempo singularizado da vida pessoal de cada associado. No plano da historicidade associativa é quase nada. Ou seja: não dá para uma detida apreciação das coisas de nosso comum interesse profissional, mormente quando se recomenda (em convite especial) abordagem temática em ritmo de "compromisso social, participação e luta". Para análise da evolução histórica e desenvolvimento associativo, a maturidade profissional não se faz plenamente sucedânea, em tempo precário de exposição para apreciar devidamente os avanços procedidos, e menos ainda para avaliar, com proveito, as lutas e conquistas efetuadas. Não sei me explico bem. Contudo, a valer o ponto de vista, sou muito crítica para endereçar, nesta ocasião, apenas as congratulações.

As evoluções históricas das entidades associativas sucedem em meio às crises da sociedade e da cultura. $\mathrm{O}$ tempo histórico, atualmente, está marcado por prementes desafios econômicos, disputas em torno de hegemonia de poder político, e é crucial a necessidade de avançar, de um modo ou de outro. Precisamos apreciar a Enfermagem Brasileira em meio a seu significativo e continuado desenvolvimento e, também, face à tonalidade de lutas ainda não inteiramente vencidas. Ou, então, - e pode até não parecer o modo mais salutar -, talvez se tenha de aguardar oportunidade que não seja de festividade para definir plenamente as coisas que nos dizem respeito. Não apenas no aspecto específico de profissionais de saúde, historicamente situados, neste tempo de hoje. Mas, pelo aspecto designado compromisso social, entendo que interessam as coisas que se fazem na prática concreta. E eu só posso falar, hoje, da elevada consideração à Associação que nos congrega, a tão bem dileta e conceituada ABEn Nacional. Enquanto isto, porém, só poderei ressaltar coisas e questões em plano de fatos sucedidos. A exiguidade de tempo não permite análise quantitativa detalhada de produtos obtidos. Colocarei, pois, somente aspectos qualitativos de circunstâncias do compromisso social na realidade, esta compreendida circunstancialmente histórica, e outros aspectos destacados do desenvolvimento e engajamento no Saber/Conhecimento Profissional. Para uma conferência, cabe-me ressaltar destaques a valer, aqui, por "pontuais avanços e conquistas, contribuições marcantes, e desafios".

A profissão de enfermeiras/os é ainda muito jovem. Surgida há pouco mais de 150 anos no bojo de nova proposta de atenção à saúde da Reforma Sanitária procedida na Inglaterra da Era Vitoriana pós-guerra da Criméia (1853-1856), - pode-se dizer -, é mesmo muito jovem. Mas, já se implantou, na realidade histórica (1860), como Saber Profissional e Paradigma fundamental modelar de preparar enfermeiras treinadas mediante crivo de princípios científicos básicos e estritas regras de Ética vazada em atitudes e condutas de que-fazer e saber-fazer as coisas com elevada responsabilidade social. Desde o início, o Sistema Nightingale de Enfermagem Moderna foi considerado contribuição maior ao processo assistencial de pertinência para enfermos e sadios. Razão justa para a formação do perfil de enfermeiras/os ser considerada fator primaz em plano de educação superior e na relevância da assistência à saúde. Graças às estratégias educacionais e tecno-artísticas norteadas por instruções sanitárias, demonstração pelo exemplo, e competências de cuidados prestados na assistência à saúde, a Enfermagem Moderna foi se expandindo mundo afora segundo o plano de perspectivas e proposta da Reforma Modernista de Florence Nightingale à profissão por ela designada "a mais bela das Belas Artes" $(1,2)$.

Em lastro de 30 anos, o modelo inglês de Enfermagem ganhou notoriedade social, e expandiu-se em território local e mundial; avançou como trabalho assistencial, consagrando o papel social e a função estrita tangíveis às competências profissionais de mulheres enfermeiras em hospitais e consultórios 
de Distritos Sanitários. A seguir, julgando-se mal pagas por suas atribuições, as enfermeiras entraram em disputas profissionais. A questão ficou assentada como a primeira crise histórica da profissão. De um lado, algumas já disputando em torno do regulamento da atividade profissional e, do lado contrário, as outras pugnando pela defesa da mística vocacional. Conforme historiadores, Florence Nightingale optou por não intervir, desde que a seu ver, na Enfermagem, antes de tudo, precisa-se sempre de vocação e dever ético.

À época, a realidade mundial já se encontrava assolada pelas reivindicações e lutas de trabalhadores de fábricas e grandes indústrias. As mulheres foram efetivamente influenciadas. As enfermeiras começaram a se organizar e criaram, em 1887, a Associação Real de Enfermeiras Britânicas, sob liderança da Sra. Ethel Bedford-Fenwick, a qual, mais tarde (1900), seria eleita Primeira Presidente do Conselho Internacional de Enfermeiras (CIE/ICN). Nessa ocasião, as Enfermeiras Nightingale já haviam decidido firmar-se em torno da Enfermagem Moderna com três vertentes: a mística vocacional, a organização associativa e a filosofia feminista. Em 1901, realizou-se o $1^{\circ}$. Congresso Internacional Quadrienal do CIE/ ICN, norteado pela palavra-chave "Trabalho".

A Enfermagem Moderna deu seu primeiro salto evolutivo, foi assumida pelas Enfermeiras Norte-Americanas, e dos Estados Unidos transplantada para o Brasil, anos 1921-1922, no bojo do movimento sanitarista e específico pleito de Carlos Chagas, médico-cientista, então Diretor Geral do Departamento Nacional de Saúde Pública (DNSP). Segundo diagnóstico e relatório situacional, a Enfermagem foi implantada (1922) e a Escola de Enfermeiras fundada (1923), consagrando-se na realidade brasileira o Sistema Nightingale de Enfermagem Moderna. E, pode-se dizer e assumir, que o modelo na prática já traz a mística da ética vocacional, a intencionalidade associativa sobre a legalidade do trabalho na profissão, e as preocupações filosóficas quanto ao papel da mulher enfermeira na sociedade. Ademais, em plano fundamental, as ações de trabalho com propósitos e objetivos de cuidados ofertados não somente aos doentes e famílias, mas também aos sadios necessitados de proteção à saúde ${ }^{(3)}$.

\section{ASPECTOS SIGNIFICATIVOS DA HISTÓRIA EM PAUTA}

Sobre a trajetória histórico-evolutiva da Enfermagem Brasileira está tudo registrado em algumas obras: "A Enfermagem Moderna no Brasil"(4), "Associação Brasileira de Enfermagem - 1926 / 1976 - Documentário"(5), "Enfermagem Brasileira Contribuição da $A B E n^{\prime \prime(6)}$, e outras. Vale relevar que em seu começo, o modelo de prática assistencial e de preparar o perfil profissional é designado Enfermagem de Saúde Pública. Modelo a se institucionalizar em base de princípios científicos, práticas de higiene, estratégias de ensinar-aprender a cuidar de enfermos e sadios, instruções assistenciais, visitação domiciliar, vigilância de enfermagem de casos individuais e grupos. Esta é, sobretudo, uma fase de assentamentos. Com algumas conquistas marcantes, as reivindicações são moderadas, em âmbito de "Missão Técnica de Cooperação para o Desenvolvimento da Enfermagem no Brasil". Muito se deve a Carlos Chagas e, sem dúvida, à Sra. Ethel Parsons (Superintendente de Enfermagem e Chefe da Missão Técnica), com a participação de enfermeiras norte-americanas e estrangeiras. Pelo Decreto No. 16.300 / 1923 (Código Sanitário de Carlos Chagas), a Enfermagem Brasileira é estabelecida e a formação profissional assegurada em estrutura e parâmetros legais. A Missão Técnica dura de 1921 a 1931.

Nesses 10 anos, o progresso é inestimável. E devemos apreço principalmente às providências da Sra. Parsons, não somente pelos avanços na concepção de cuidar e assistir, na Enfermagem de Saúde Pública e na assistência hospitalar, mas também pelo interesse em plano de refinar a preparação de agentes visitadoras sanitárias a reforçar o pessoal dos Distritos Sanitários. E não custa lembrar seu esforço pessoal no recrutamento e Apelo às Moças Brasileiras para efetivar o ingresso de Alumnas na Classe de Enfermeiras e, ainda, pela regulamentação da prática profissional, segundo o Decreto No. 20.109 / 1931, considerado Primeira Lei do Exercício da Enfermagem Brasileira. Esse Decreto, além de regulamentar o exercício da profissão, serviu à revalidação de diplomas estrangeiros, à equiparação de Escolas existentes ou a serem criadas conforme o padrão Anna Nery, este servindo de eixo legal no país, para parâmetro de formação profissional e acordos com o Sistema Nightingale. No que interessa ao lado assistencial, de tão adequado, esse Decreto manteve sua vigência até a conquista e promulgação da Lei No. 2.604 / 1955.

Cabe referir, que a Sra. Parsons auxiliou na criação da Associação Nacional de Enfermeiras Diplomadas Brasileiras (ANEDB). Pois, em 1926, quando as enfermeiras recém diplomadas, - Classe das Pioneiras (1925) -, já se organizavam para criar a Associação de Ex-Alunas, - ela mesma (Sra. Parsons) -, ajuizou em favor de uma entidade associativa mais ampla que pudesse congregar todas as enfermeiras diplomadas, inclusive as estrangeiras efetivamente aprovadas por exame de revalidação. O fato sela a primeira crise na Enfermagem Brasileira, mas as jovens enfermeiras conformam-se face aos argumentos da Sra. Parsons e entregam os rascunhos de seu pretendido Regimento para efetivar o novo Regulamento associativo. Com isso, a recém-criada entidade pôde pleitear, em 1929, afiliação ao CIE/ICN, órgão já institucionalizado para assegurar a participação de enfermeiras em eventos internacionais e discussões de temas, questões e programas de interesse da Enfermagem no mundo.

A consolidação do reconhecimento social de uma profissão guarda relação íntima com sua competência técnico-científica, com sua organização política e efetiva contribuição social. A literatura pode não ser tão farta, mas é valiosa. Aos mais interessados, cabem consultas tangíveis a Os Primórdios da Enfermagem Moderna no Brasil da autoria de Barreira ${ }^{7}$.

No meu caso, aqui, sumarizar pode ser um mal, mas é preciso. Vale dizer, pois, que o DNSP sofreu transformações políticas e novas localizações ministeriais, com o que a Escola de Enfermagem Anna Nery também sofreu mudanças, mas galgou, afinal, o patamar do ensino de nível acadêmico-universitário - plano da Universidade do Brasil (atual UFRJ) - graças à Lei No 452 / 1937. A História da Associação de Classe comprova os primeiros saltos evolutivos da profissão, 
quando as enfermeiras brasileiras pioneiras estavam prontas para empreender lutas e avanços, efetivar conquistas e promover contribuições à Enfermagem e à sociedade.

Nas décadas de 1930 a 1950, o Modelo Parsons expandiu-se pelo país. A despeito das novas pressões políticas sobre a saúde como compromisso social, mormente por conta, naquela ocasião, dos efeitos do novo e crescente sistema previdenciário e disposições normativas sobre atenção médico-hospitalar, a EEAN e a ANEDB foram se desenvolvendo como possível. Mas, a profissão avançou, comprovando evolução, primeiro pela criação e divulgação do periódico Annaes de Enfermagem (1932) e, depois, pela realização de

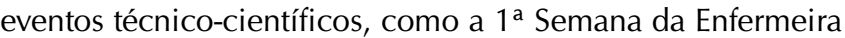
(EEAN, 1940) e $1^{\circ}$ Congresso Nacional de Enfermagem (São Paulo, 1947). Também graças aos esforços conjugados entre a Associação e Escolas de Enfermagem, as lutas em favor da profissão passam a ser mais bem direcionadas. Alguns Cursos são reconsiderados ou equiparados, outros surgem como novos, e a entidade associativa começa a reorganizar-se com implantação de ABEn-Seções Estaduais. Nesse contexto, o ensino de enfermagem modifica-se com a promulgação da Lei No. 775 / 1949, a qual, além de regular a criação dos Cursos de Auxiliares de Enfermagem, acarretou mudanças para a Graduação em Enfermagem. Principalmente, porque a atenção médico-hospitalar é relevada em sua importância em detrimento da anteriormente designada atenção e proteção à saúde populacional.

Em 1953, no Rio de Janeiro (Cidade de Petrópolis), realiza-se o X Congresso Internacional Quadrienal do CIE/ICN, onde se discute e aprova-se o Código Internacional de Ética de Enfermagem. E, com o VII Congresso Nacional de Enfermagem (São Paulo 1954), a entidade associativa passa a denominar-se Associação Brasileira de Enfermagem (ABEn) e seu órgão de divulgação passa a denominar-se Revista Brasileira de Enfermagem (REBEn). Daí, então, os esforços associativos ampliam-se e a profissão dá novo salto evolutivo na dependência de mais ativa contribuição dos participantes. Tenha-se atenção, no entanto, às preocupações com a situação profissional coerente às demandas assistenciais de saúde e à responsabilidade cabível aos exercentes e trabalhadores da área da Enfermagem, sobremodo pela questão dos atendentes. Toda essa questão é testemunhada com o empreendimento investigativo Levantamento sobre Recursos e Necessidades de Enfermagem no Brasil(8) - (Coordenação de Haydée Guanais Dourado) -, realizado com patrocínio da Fundação Rockefeller, Organização Mundial de Saúde - OMS e Instituto Brasileiro de Geografia e Estatística - IBGE (1956-1958). Com sua divulgação (1962-1963), além de exemplar, o fato tem expressão para o início da investigação e produção científica e para a primeira avaliação crítica da prática profissional.

No plano histórico, e em relação à situação total da prática profissional, não se pode perder de vista a contribuição marcante de pertinência científica com a Tese "A Enfermagem Moderna como Categoria Profissional: Obstáculos à sua expansão na sociedade brasileira"(9), apresentada em Concurso e Defesa de Título de Professor Catedrático de História da Enfermagem e Ética (atual Professor Titular), primeiro a ser obtido por enfermeira no Brasil (1963). Essa tese consolidou, em bases sólidas, na Universidade de São Paulo - USP, a Escola de Enfermagem de Ribeirão Preto (EERP/USP).

Até o final de 1960, pelo ensino de Enfermagem a cada dia mais sofisticado, e pela necessidade de desenvolver a produção científica pela pesquisa, fica evidente a necessidade de efetivar a qualificação de docentes para atuação nos programas de nível universitário. Nessa mesma década, a temática pesquisa em enfermagem é incluída nos programas dos Congressos. Sucede então, em plano de magistério superior, por força do Parecer CFE No 77 / 1969, o evento de Concursos de Livre Docência, pelo qual novo salto evolutivo pode ser justificado. Nesse caso, sobretudo, cabe destaque não só pelas temáticas, mas pelo marcante início desses concursos, na EEAN/UFRJ (1968), com duas teses "A Observação Sistematizada na Identificação de Problemas de Enfermagem em seus aspectos físicos" (Horta ${ }^{10}$ ) e "Enfermeiros para o Nordeste em Desenvolvimento - Assistência de Enfermagem e Educação" (Dourado ${ }^{11}$ ). E, em 1977, novos concursos são realizados na EEAN/UFRJ, quando várias enfermeiras alcançam título de Doutor mediante tais Concursos de Livre Docência.

\section{LUTAS REIVINDICATÓRIAS E CONQUISTAS PROGRESSIVAS}

Os anos de 1960 foram cruciais, pelas crises demarcadas por embates políticos e disputas reivindicatórias em favor da educação na área da Enfermagem. Apesar dos desafios, sucederam muitos avanços e conquistas marcantes, graças aos esforços conjugados da Associação e Escolas de Enfermagem. Mas houve muita polêmica e reivindicações aliadas à Lei de Diretrizes e Bases da Educação Nacional (LDB). Apesar de restrições da política militar e pressões consequentes, o Ensino de Enfermagem é alterado, principalmente, por novas disposições, - Parecer CFE No. 271 / 1962 e Parecer CFE No. 303 / 1963 -, com os quais se alteram, sobremodo, a estrutura curricular em nível de Graduação. O primeiro Fixa o Mínimo do Curso de Enfermagem, modifica conteúdo e carga horária e elimina a Enfermagem de Saúde Pública. O segundo Fixa o mínimo de Obstetrícia e estabelece critérios em relação ao desenvolvimento do programa e interesses gerais da área de Enfermagem.

No final desta década e início da seguinte, sucederam dois eventos - com colaboração e patrocínio da Organização Pan-Americana de Saúde (OPAS/OMS) - para ampliar a discussão sobre educação, a situação curricular e a formação de enfermeiras/os. O primeiro, em São Paulo, - Seminário Nacional sobre Currículo do Curso de Enfermagem (EE/USP, 1968), e o segundo, em Ribeirão Preto SP, designado I/ Seminário sobre Educação em Enfermagem (EERP/USP, 1970). Os dois eventos com grande participação e atividades em assembleias e grupos de discussão. A polêmica foi incisiva em torno de papel, função e competências de enfermeiras/os, com enfoque na Graduação, e com decisivo questionamento sobre o que-fazer e o saber-fazer aliados à sistemática assistencial e cuidado de enfermagem nas instituições sanitárias e hospitalares. Não dá para detalhar. Porém, nessa ocasião (1970) surgiu, pela primeira vez, a questão e temática do processo de enfermagem. 
Podem-se obter mais informações do apoio bibliográfico nos relatórios dos ditos eventos.

Todavia, aos interessados em História da Enfermagem e disciplinas afins, vale dizer que essa questão mobilizou todas as Escolas de Enfermagem e todas as Seções da ABEn para efeito de reivindicações junto ao Ministério da Educação e Cultura (MEC), inclusive em razão de lutas continuadas em torno da formação de obstetrizes pelos médicos. Contudo a situação do ensino se agrava com novas lutas políticas pela indicação da necessidade de criar os Cursos Técnicos de Enfermagem a partir de 1966, inclusive por força da ideia de ampliar o contingente da força de trabalho na Enfermagem. A situação parece mais aguda pela necessidade de capacitar melhor o pessoal de docência para o ensino de $1^{\circ}$ e $2^{\circ}$ Graus. A situação de lutas e potenciais avanços, nesse particular, perdurou até início dos anos 1970, os quais demarcados por outras polêmicas e lutas a exigir o advento de novos instrumentos legais para favorecer os parâmetros quantitativos e qualitativos e a regulamentação das ações educacionais, com estratégias pedagógicas imprescindíveis aos avanços profissionais na realidade brasileira. Por tudo isso, ficou patente a necessidade de revigorar-se a força de lutas e a defesa da profissão.

$\mathrm{E}$, então, novos desafios, pois todas essas lutas serviram, também, de eixo para a criação de novas associações profissionais de objetivos trabalhistas e propósitos sindicais a partir de 1962 (Bahia, Sergipe, Goiás, Rio de Janeiro, Ceará, e Rio Grande do Sul). As reivindicações configuram verdadeiros desafios mais dificultados por restrição da política militar. E, só a partir dos anos 1970, as conquistas foram efetivadas em que pese os aspectos significativos das lutas pró-sindicatos. Mas, devido ao constrangimento da política governamental, ABEn e Escolas de Enfermagem priorizam seus pleitos reivindicatórios quanto aos assuntos curriculares e educacionais, e a necessidade precípua de enfrentar mais desafios e novas conquistas legais. Entretanto, cabe mencionar que as lutas pró-sindicatos culminam em atendimento aos pleitos profissionais e, afinal, a Enfermagem Brasileira consegue dar mais um salto evolutivo, porquanto a partir de 1971, com a abertura política, os Sindicatos Estaduais de Enfermeiros conseguem registro e ação livre na proteção dos direitos dos trabalhadores de enfermagem.

Mas a tonalidade das lutas a congregar pleitos associativos e reivindicações de Escolas de Enfermagem, à época, parece sempre de pouca monta para determinar os avanços desejados. Tenha-se em conta os prementes desafios da situação brasileira face à Lei No. 5.540 / 1968 e as implicações da Reforma Universitária. As lutas conjuntas - ABEn e Escolas de Enfermagem - ampliam-se em razão dessa Lei a impor a obtenção de novos instrumentos legais para refinamento da formação profissional de nível superior. E, mais ainda, porque a Pós-Graduação lato sensu, nos termos do Aperfeiçoamento ou da Especialização de Enfermagem, já não satisfazia aos objetivos de formar o perfil profissional desejado para enfermeiras/os. E, sem dúvida, a questão intensifica-se pela necessidade de melhor qualificação para o pessoal dedicado ao ensino de enfermagem, bem como havia que se enfrentar o desafio da necessidade de ensino e aprendizagem pela Pesquisa na Enfermagem na programática curricular, e desde a
Graduação. Porém, mesmo com este destacado salto evolutivo a necessidade de enfrentamento da questão é premente nos aspectos específicos. É quando - representantes de Escolas de Enfermagem (EEAN e USP) -, com colaboração da OPAS/ OMS, discutem a situação da Enfermagem, na área da saúde, pela necessidade de subscrevê-la aos parâmetros das Linhas de Pesquisa. E tenha-se em conta disposições do II PBDCT 1974, definindo Pós-Graduação e Pesquisa Fundamental na área das Ciências da Saúde (Coura e cols. ${ }^{12}$ ).

\section{AVANÇOS NA GRADUAÇÃO E PÓS-GRADUAÇÃO STRICTO SENSU E OUTROS}

Nesse contexto, cabe relevância ao fato da Reforma Universitária de 1968 (Lei № 5.540 / 68) ter imposto revisões de todos os Currículos Mínimos de Graduação. A conquista da Enfermagem Brasileira é selada com o Parecer CFE No 163 / 1972, o qual, - Fixa o Mínimo dos Cursos de Enfermagem e Obstetrícia -, regulamentado pela Resolução CFE № 04 / 1972. Esses instrumentos permitem reconsiderar-se o perfil profissional e a formação de enfermeiras/os, de modo a abranger as ciências básicas, as disciplinas profissionais comuns e a parte das "habilitações específicas" - Enfermagem de Saúde Pública, Enfermagem Obstétrica e Enfermagem Médico-Cirúrgica, incluindo-se ao lado das mesmas a Licenciatura de Enfermagem. Porém, tais instrumentos legais e modificações curriculares consequentes não alcançam consenso e contentamento geral. Novos conceitos de formação de "generalistas" para atuação assistencial em plano de "ações integradas" não foram pacificamente aceitos em plano geral, e colocaram em causa a saúde individual e coletiva. Mas, os esforços da Associação e Escolas de Enfermagem foram devidamente mobilizados nas tentativas de adequar as novas disposições curriculares à realidade legalmente imposta.

Todavia, de intermédio com novos desafios da Pós-Graduação stricto sensu, vale colocar que enfermeiras/os, no plano geral da política associativa e acadêmica, ainda ressentiam-se de certa fraqueza de forças para os embates na contingência de novas lutas pelo ensino e assistência de enfermagem. Mais precisamente, pode-se afirmar de certa precariedade de argumentos e firmeza de posição nas reivindicações para resguardar legalmente a fiscalização do exercício profissional de enfermagem em nível equânime ao poder supostamente assegurado às outras profissões da saúde, mesmo com todas sob o poder e controle do Serviço Nacional de Fiscalização da Medicina e Farmácia - SNFMF. Todos os esforços foram endereçados à defesa de pleitos constantes em memorial referente a um sistema legal compatível, - em plano da própria entidade associativa -, ao tratamento e ajuizamento ou julgamento ético consistente com as questões assistenciais na Enfermagem. E, então, é quando se conquista a Lei No. 5.905 / 1973, a qual dispõe sobre a criação do Conselho Federal de Enfermagem - COFEN e dos Conselhos Regionais de Enfermagem - COREN(s), compondo um sistema legal capaz de "disciplinar, fiscalizar e registrar" o exercício profissional de todos os exercentes na Enfermagem. Não se pode minimizar, este um grande salto evolutivo em favor da prática profissional. 
Ao lado dessas lutas, as discussões para desenvolver melhor a Graduação continuam. A década de 1970 é demarcada por continuadas polêmicas. E demandaram esforços conjuntos e acordos, regionalmente e nacionalmente, em Seminários de Ensino de Enfermagem, Oficinas e Grupos de Trabalho, com apoio da Comissão de Especialistas de Enfermagem - SESU/ MEC, mais decisivamente de 1986 a 1991. Merece destaque o fato dos esforços da ABen Nacional, encaminhando ao MEC memorial e proposta de revisão do Parecer CFE No 163 / 1972. E, assim, a Enfermagem Brasileira, em 1994, conquista novo Currículo Mínimo segundo Parecer CFE No. 314 / 1994, com sua regulamentação assegurada pela Portaria CFE No. 1721 / 1994. Sob força de tais instrumentos, as diretrizes curriculares pareciam assegurar proporcionalidade adequada de novas competências ao desejado refinamento do perfil profissional de enfermeiras/os, - nível de Graduação -, e de sorte a atender aos princípios lógicos de consistência e coerência com parâmetros e objetivos do Sistema Único de Saúde - SUS (Brasil ${ }^{13}$ ).

Cumpre dizer que, a partir do surgimento, no Brasil, da Pós-Graduação stricto sensu, a área da Enfermagem fica mais convulsionada com a implantação do Mestrado (EEAN/UFRJ / 1972), inicialmente demarcado por expectativas de refinar a qualificação de enfermeiras/os para a docência na Graduação e com o ensino a responsabilizar-se por projetos de investigação. Posteriormente, a questão da Pesquisa na Enfermagem assume tal importância, que a ABEn se decide pela organização e realização do Seminário Nacional de Pesquisa em Enfermagem - SENPE, sendo os dois primeiros realizados em Ribeirão Preto SP (1979) e Brasília DF (1982). Isto, realmente grande salto evolutivo, posto que a cada dois anos, o evento vem se desenvolvendo com participação de estudantes, professores e pesquisadores, com apresentação - relatos e mostras - configurando projetos de pesquisa e resultados de pontuais avanços e conquistas marcantes para o domínio do Saber/Conhecimento Profissional.

O Doutorado em Enfermagem é implantado na USP, a partir da década de 1980, primeiro no Brasil e América Latina, e visando sobremodo a preparação formal para a investigação e desafios da produção científica pela Pesquisa na Enfermagem. Com a situação mais expandida, inicialmente na Região Sudeste, a Pós-Graduação, com cerca de 50 Cursos, desenvolve-se gradualmente. Os programas ampliam-se, atualmente, por várias regiões do país. Graças aos esforços conjuntos em plano de redes de intercâmbio institucional, congregando docentes de Universidades face aos novos objetivos dos designados Cursos de Mestrado e Doutorado, mais comumente designados Minter e Dinter. Pelos respectivos programas e objetivos, os programas são acompanhados e avaliados segundo critérios e acordos ministeriais (CAPES/MEC).

Paralelamente, a situação geral pode ser avaliada pelos relatórios dos Cursos de Pós-Graduação stricto sensu e, naturalmente, mediante produtos, - dissertações e teses -, como registradas no Centro de Estudos e Pesquisas de Enfermagem (CEPEN / $A B E n)$. Este órgão publica os catálogos de Enfermagem, - Informações sobre Pesquisas e Pesquisadores de Enfermagem -, nos quais constam resumos de produções científico-acadêmicas dos Programas de Pós-Graduação. O acervo segundo dados da
ABEn (2010) confere com mais de 6.800 produções divulgadas (impressos e CD), dados que na expressão das temáticas podem demonstrar efetivo salto evolutivo da Enfermagem na construção do Saber/Conhecimento Profissional.

\section{PELA NECESSIDADE DE UMA CONCLUSÃO}

Não é possível avaliar todos os relevantes empreendimentos associativos nos desafios de crises temporais, e como manifestação de verdadeiros saltos evolutivos. Mas, cabe ressaltar, aqui, toda a consideração histórica a fatos sucedidos nesses anos de 1980 adiante, fatos bem expressivos na conjuntura de eventos políticos e científicos. Mormente, a exemplo de estudos como pesquisa e consequente produção científica, cada vez mais desenvolvida em trabalhos da lavra de pesquisadores enfermeiras/os interessados em temas conferindo com "Avaliação e Perspectivas" ou associados em "Áreas de Atuação, Linhas de Pesquisa e Prioridades"(14).

Não dá para detalhes, a exiguidade de tempo é um embargo. Lamentavelmente, as questões do exercício profissional, aqui no Brasil, mais do que antes, - e todos sabemos disso -, apresentam-se convulsionadas por precárias condições nas instituições de saúde, deficiência de autonomia profissional de enfermeiras/os, terceirização de cuidados de enfermagem, e insuficiência educacional na preparação de pessoal. A situação geral pode ser analisada em investigações e estudos conjuntos, - (1982/1983) -, conferindo com preocupações de entidades - (COFEN/ABEn) - sobre "O Exercício da Enfermagem nas Instituições de Saúde do Brasil", cuja divulgação emerge em dois volumes - Força de Trabalho de Enfermagem (vol I) e Enfermagem no Contexto Institucional - vol. II(15).

Evidentemente, de permeio ainda há fortes razões para não se esquecer o significado valioso de pontuais avanços e conquistas, os desafios de lutas para a obtenção de novos instrumentos legais que possibilitam avaliar os esforços conjuntos em favor de dinamizar-se Exercício e Prática da Enfermagem, nos termos da Lei $N^{0} 7.498$ / 1986 e Decreto $N^{0} 94.406 /$ 1987. Legislação essa que, além de regulamentar a profissão, inclui a categoria do "técnico de enfermagem", elimina "o atendente de enfermagem" e dispondo, também, sobre o tempo autorizado para a profissionalização de exercentes do sistema informal de ensino. Em torno dessa questão, tampouco se deve esquecer as lutas sucedidas mediante esforços conjuntos de Escolas e Faculdades de Enfermagem, ABEn e COFEN, entidades sindicais, e Ministério da Saúde.

Cumpre referir, ainda, em relação às lutas associativas sobre legislação e normas legais de Enfermagem que a ABEn participou de reuniões junto ao CIE/ICN conferindo com temas sobre A Regulamentação da Enfermagem. Isto, em três Seminários Internacionais Região do Caribe e América Latina, realizados em Quito, México e Porto Rico, para tratar da pertinência dos assuntos aliados ao compromisso social e legal da Enfermagem na realidade do mundo (1987-1991).

No mais, cabe atenção à trajetória evolutiva dos eventos científicos e Congressos realizados a partir dos anos 1990 em diante, tanto em plano local como internacional, mormente pelos Congressos Brasileiros de Enfermagem já realizados 
(63). Os mais recentes falam pelas marcantes conquistas alcançadas sobre regras de mudanças científicas, de comunicação, intercâmbio e acordos sobre refinamento da preparação de enfermeiras/os, mormente pela coerência com requisitos de pesquisa, produção e divulgação científica. A preparação profissional, bem mais refinada pela Pesquisa na Enfermagem, pode ser apreciada em Anais, Livros/Programas de eventos e nos periódicos indexados. Ademais, cabe menção às continuadas preocupações com a preparação profissional, especialmente na Graduação, e como especificamente tangível aos desafios da "função de cuidar" e "papel social" face aos termos e novos conceitos de Globalização e Competitividade ${ }^{(16)}$.

Não há como apreciar todos os desafios e lutas atuais. A ordem e a lei impõem-se agora pela economia de mercado, bem como são mais válidas as recomendações de aprimoramento de estratégias profissionais para específica e necessária consistência com o enfrentamento dos anos futuros adiante. Seja em razão de reconsiderar possibilidades de sérios embates decorrentes dos anos do final do século XX, ou como previstos até nas antecipadas mudanças de paradigma relativamente à formação profissional e aos desafios relativos aos cuidados de enfermagem nos anos próprios deste III Milênio. Como se sabe, o papel social e a função de enfermeiras/os em plano de realidade concreta estão em pauta e em questionamento. Mas, a visão de mundo em meio ao turbilhão de mudanças às vezes não é tão perfeita. Esta questão merece urgente reconsideração da situação da Enfermagem como um todo.

Nesse sentido, ainda cabe atenção a dois aspectos. O primeiro, acerca da importância associativa de contribuição marcante à realidade da Enfermagem e à sociedade. Penso que somente os que vivem e tratam da História da Associação Brasileira de Enfermagem podem falar dos pontuais avanços e conquistas, supostamente compreendidos, por detrás e nos meandros a demarcar, mais estritamente, os fatos tais como sucedidos no espaço temporal de 85 anos. Se as coisas do interesse comum mudaram tanto, mais ainda mudarão em tempo de futuro. $\mathrm{O}$ segundo aspecto é tangível às lutas que envolveram muitos associados na internalidade do âmbito da profissão. Todos dedicadamente interessados na intencionalidade ética da mística da enfermagem, nos valores e objetivos da participação associativa, e no engajamento decidido com o compromisso social de profissionais influenciados ou submetidos às lutas pela profissão e aos desafios do papel da mulher na sociedade. No que me concerne - afeita às reflexões críticas e à racionalidade da sensibilidade do coração -, prefiro não jogar com dados potencialmente influenciados por ideologia associativa. Alguns de nós, certamente afirmam - talvez tenham certa razão -, que a ABEn mudou muito em seu ritmo e modo de atuação como entidade associativa. Isto, afinal, faz parte das mudanças - históricas e de desenvolvimento social -, mudanças na evolução da vida associativa, afetando a todos nós.

Por último, mas não por fim, à conta do que foi possível documentar, aqui, em plano de simples e sumário relato, eu só posso afirmar o que se justifica como razão suficiente ou por critérios de apoio à subjetividade crítica. Mas, este assunto e como aqui exposto, não está esgotado. Em realidade, sinto-me influenciada pela fé de ofício a demarcar o amor à profissão de enfermeira. Aos que se ocupam da História baseada em pesquisas realizadas com objetivos específicos, cabem a atenção e os investimentos de esforços investigativos em favor dos detalhes, dos desafios e de outros resultados de lutas já vencidas ou a serem vencidas em tempo de futuro secular. Não temos como escapar dos novos desafios nas possibilidades do tempo do tempo - (tempo de Deus) - demarcado por limites e possibilidades de mais lutas e novas conquistas, plenas de potenciais e significativos desafios próprios do eterno tempo do ad-vir. E, aqui, vale colocar um especial destaque quanto a finalizar minha simples contribuição. Tal como penso, a todos nós enfermeiras/os cabem a intencionalidade ética, a participação associativa e o dever profissional quanto aos interesses do compromisso social. E, depois, só mesmo Deus para nos destinar mais pontuais avanços e conquistas marcantes no plano desta inefável Associação Brasileira de Enfermagem (ABEn), no desenvolvimento secular de sua História e, portanto, decisivamente merecedora de nossos "Parabéns".

Mas, ainda valem algumas palavras. Cumpre-me apresentar uma palavra especial às digníssimas Sras. Presidentes - da ABEn Nacional e ABEn Seções -, e também a todos os associados que contribuíram ou contribuem, efetivamente, para a relevância associativa. Todos são merecedores de nossas congratulações. E falo pelos que estão ainda vivos e pelos já transpostos à casa do Pai. E estão aqui, pois, os meus mais sinceros votos festivos a todos os que souberam ou sabem lutar e vencer pelos gáudios e conquistas de bem vividos 85 Anos de tão relevante História em plano de realidade brasileira.

\section{REFERÊNCIAS}

1. Seymer LR, Guinsburg J, tradutor. Florence Nightingale - Pioneira da Enfermagem e Precursora da Emancipação Feminina. São Paulo: Edições Melhoramentos, s.d.

2. Dolan JA. Nursing in Society - a historical perspective (thirteenth edition). Philadelphia: W. B. Saunders Company; 1973.

3. Carvalho V. A Enfermagem de Saúde Pública como Prática Social - Um ponto de vista crítico sobre a formação da enfermeira em nível de graduação. 1997;1(n. ${ }^{\circ}$ esp.):161-76.
4. Parsons E. A Enfermagem Moderna no Brasil (fac símile). Exposições e Relatórios / Archivos de Hygiene. Esc Anna Nery Rev Enferm 1997;1(n. ${ }^{\circ}$ esp.):161-76.

5. Carvalho AC. Associação Brasileira de Enfermagem: 1926/1976 - Documentário. Brasília: ABEn; 1976.

6. Paiva MS, coordenadora, et al. Enfermagem Brasileira Contribuição da ABEn. Brasília: ABEn; Nacional; 1999.

7. Barreira IA. Os Primórdios da Enfermagem Moderna no Brasil. Esc Anna Nery Rev Enferm 1997;1(n. ${ }^{\circ}$ esp.):161-76. 
8. Associação Brasileira de Enfermagem (Brasil) Levantamento sobre Recursos e Necessidades de Enfermagem no Brasil. Rio de Janeiro: ABEn; 1963.

9. Alcântara G. A Enfermagem Moderna como Categoria profissional: obstáculos à sua expansão na sociedade brasileira. Ribeirão Preto. Tese [Concurso de Cátedra em História da Enfermagem e ética]- Universidade de São Paulo; 1966.

10. Horta WA. A Observação Sistematizada na Identificação de Problemas de Enfermagem em seus aspectos físicos. Rio de Janeiro. Tese [Concurso Público de Livre Docência]- Universidade Federal do Rio de Janeiro; 1968.

11. Dourado HG. Enfermeiros para o Nordeste em Desenvolvimento - Assistência de Enfermagem e Educação. Rio de Janeiro. Tese [Concurso Público de Livre Docência]- Universidade Federal do Rio de Janeiro; 1968.

12. Coura JR, coordenador, organizador. Plano Básico de Desenvolvimento Científico e Tecnológico: Pesquisa Fundamental e Pós-Graduação / Ciências da Saúde II PBDCT 1974 Secretaria de Planejamento da Presidência da República / Ministério da Educação e Cultura / CNPq. Brasília: Ministério da Educação; 1974.

13. Ministério da Saúde (Brasil) Relatório Final da $8^{\mathrm{a}}$ Conferência Nacional de Saúde. Brasília: Ministério da Saúde; 1986.

14. Conselho Nacional de Desenvolvimento Científico e Tecnológico, Associação Brasileira de Enfermagem (Brasil) Avaliação \& Perspectivas Relatório do II Seminário Nacional sobre Ensino de Pós-Graduação e Pesquisa em Enfermagem (24 a 26/03/82). Brasília: CNPq/ABEn; 1982.

15. Conselho Federal de Enfermagem, Associação Brasileira de Enfermagem (Brasil) O Exercício da Enfermagem nas Instituições de Saúde do Brasil 1982/1983 (A Força de Trabalho na Enfermagem vol. I e Enfermagem no Contexto Institucional vol. II). Rio de Janeiro: COFEN; 1985.

16. Carvalho V. Globalización y Competitividad. Esc Anna Nery Rev Enferm 2011;15(1):171-9. 